structure of the pharynx and of a portion of cesophagus was obvious.

The stomach and intestines were in a natural state, but extremely contracted, as might be supposed.

\section{TRANSLATION OF RICORD.}

\section{To the Editor of THE LANCET.}

SIR:-Permit me to state, in reply to your correspondent "Alpha," in last week's LANCEr, that in Mr. Langston Parker's smail work, "The Modern Treatment of Syphilitic Diseases," will be found the opinions and practice of M. Ricord, which that distinguished surgeon kindly furnished to the author.

Allow me to refer to the favourable review of Mr. Parker's work in The Lancet of February 15. I am, Sir, your obedient. servant,

Princes-street, Soho, June 16, 1840.

\section{John Churchill.}

\section{JALAPINE.}

Dr. Barnes, of Sydenham College, in his Lectures on Materia Medica, makes the following observations relative to this sub. stance :-

"Jalapine, or the gum-resin of jalap, varies according to the quality of the drug; but, taking an average of the whole, it is in the proportion of about 15 per cent.; or, as a dose, one grain and a half of the jalapine to ten grains of the jalap. Like all resins, it is solnble in alcohol, æther, pure alkalies, strong acetic acid, \&c."

\section{ANOTHER SUCCESSOR FOR MORISON.}

A Hint of Vast Importance.-At two o'clock, A.M., of the 9ih inst., Dr. Horn, 13, Canuon-street, was called to visit-whom? $\Lambda$ dead man! Dr. H. maintains that the generality of sudden deaths are apoplectic, and if prompt and copious phlebotomy is not practised, death will inevitably be the consequence. Apoplexy, he remarks, has been very prevalent of late. Was the disease accurately known when it existed, and the remedy duly appreciated, and seasonably practised, many, very many valuable lives would have been saved! The skilful physician can very readily foretel an approaching attack, and he can, by the self-same remedy, prevent the confirmed attack of this alarmingly fatal disease.

The above is the result of twenty.five years'successfal practice, in the West Indies and at home. Even in this town, during Dr. H.'s residence of two years, he has been called in to several cases of threatened as well as confirmed apoplexy. All recovered. -Preston Chronicle.

\section{MEDICAL REFORM.}

Mr. Carmichael, of Dublin, has placed at the disposal of the Council of the Medical Association of Ireland the sum of $£ 500$, " to be applied to the carrying out of an ample and complete measure of medical reform."

\section{SEROUS SECRETIONS.}

On the 13th of January of this year, M. Guerin presented a paper to the Royal Academy of Sciences of Paris, in which he proposed to establish as a fact, that atmo. spheric pressure performed an important part in the function of secretion from the serous membranes, in the human body.Archiv. Gen, de Med.

\section{BOOKS RECEIVED.}

A Practical Essay on the Disease gene. rally known under the name of Delirium Tremens, written principally with a View to elucidate its Division into Distinct Stages, and hence to simplify its Method of Cure. By Andrew Blake, M.D., M.R.C.S., Phy. sician to the Nottingham and Nottinghamshire General Lunatic Asylum, \&c. Secoud Edition, revised and much enlarged. London: Longman and Co. pp. 112.

The Transactions of the Provincial Medi. cal and Surgical Association. Instituted 1832. Vol. VIII. London: Churchill, pp. 435, with 35 plates.

A System of Anatomical Plates, with De. scriptive Letter-press. By John Lizars, F.R.S.E. Parts 10 and 11 .

\section{TO CORRESPONDENTS.}

A Medical Student will find an answer to his questions, in the body of this week's Journal.

The communication from $M r$. Oren has been received, but, from its length, we have not yet had time to read it.

The letter of $\mathrm{Dr}$. Sigmond was not received until Wednesday.

$M$. D., who writes respecting $M r$. Owen, shonld exercise some research in the Museum to prove his case, and then, illustrating it by facts, expose the abuse that he castigates in his letter.

$M r$. Wickhum's note respecting the Anew. rism of the Arteria Innominata, came to hand too late for insertion in this week's Journal; it shall appear in our next.

Errata.-In the last number, p. 424, col, 2 , line 2 , for " fairness," read fitness; line 20 , for " examination degrees," read examinution for degrees. 